\title{
Lean into Clinical Pharmacy: An Experience in Implementing Key Performance Indicators and Gemba Walks into Clinical Pharmacy Services
}

\author{
Jocelyn Owusu-Guha, PharmD, BCCCP; Connie H. Yoon, PharmD, BCPS; Jordan V. DeWitt, PharmD, BCPS, BCCCP; \\ Pamela L. Buschur, PharmD, BCPS; Jennifer Bauer, PharmD, BCPS, BCCCP; Adam Smith, PharmD, BCPS, BCCCP; \\ Abby Tyson, PharmD, BCPS \\ Department of Pharmacy Services, OhioHealth Riverside Methodist Hospital
}

\begin{abstract}
Purpose: The Lean methodology was applied to clinical metrics by a critical care pharmacy team. The experiences associated with the development and implementation of clinical metrics and their impact on daily workflow are described.

Summary: The Lean methodology has been introduced into the healthcare system as a means of process improvement, which can eliminate waste through appropriate medication utilization. At OhioHealth Riverside Methodist Hospital, the department of pharmacy was tasked with the development of clinical metrics after a health system wide Gemba walk was initiated. The pharmacy department's critical care team developed a strategy identifying and evaluating clinical metrics pertaining to their everyday workflow. Each clinical metric was evaluated in accordance with a pre-defined goal. Metrics requiring heavy documentation and those in which the pharmacist does not have autonomous authority to manage were often challenging to implement and were less successful. Throughout this process, the lessons learned focused on generating ideas that were easily documented, evidence-based, and department specific. The critical care team discovered that the outcome of the most successful metrics highlighted clinical pharmacist value and data generated could be used to support funding for additional resources.

Conclusion: The critical care pharmacy team developed a streamlined process to implement clinical metrics as means of identifying areas for improvement using the Lean methodology.
\end{abstract}

Keywords: Lean methodology, key performance indicators, critical care

\section{BACKGROUND}

In healthcare, maximizing safety and efficiency while minimizing waste is paramount. The implementation of Lean principles to improve patient care and operational quality through reduction of waste has become standard practice. The Lean methodology is the application of ideas and management principles centered around eliminating waste and non-value adding activities. ${ }^{1}$ Initially developed by the Toyota Production System in the 1930s, the Lean thought process was founded in an effort to streamline production. The concept of Lean was further refined into five principles, which are, define value, map the value stream, create flow, establish pull, and seek perfection. Increasingly, healthcare systems implement Lean promotion groups to educate personnel and departments on establishing Lean practices through metric development. Areas of waste can be identified at any point in a patient's hospitalization and throughout various departments to optimize procedural processes and the patient experience..$^{2-3}$

Corresponding author: Jocelyn Owusu-Guha, PharmD, BCCCP Clinical Pharmacist, Neurocritical Care

Riverside Methodist Hospital 3535 Olentangy River Road, Columbus, Ohio 43214

Email: Jocelyn.Owusu-Guha@OhioHealth.com
The Lean methodology often involves the participation of key stakeholders in Gemba walks and Kaizen events. Daily Gemba walks, based on a Japanese term meaning "where the work occurs," have become increasingly popular as a part of the inpatient Lean process impacting pharmacy services. ${ }^{4}$ Similarly, Kaizen events, based on a Japanese term meaning "continuous improvement," bring together key stakeholders to evaluate activities that do not add value to a process or the organization. ${ }^{5}$ The current practice involves identifying areas for improvement within the department of pharmacy and systematically discovering any areas of waste. Since the origins of the Lean principles were founded on manufacturing principles, application to the inpatient pharmacy setting is often focused on operational tasks, which may not always overlap with clinical tasks. Clinical pharmacy tasks are often focused on process improvement which can eliminate waste through appropriate medication utilization.

As it pertains to clinical pharmacy services, the Lean methodology has been trialed in various pharmacy settings. ${ }^{6}$ Notably, a 2013 study described a "waste walk" evaluating clinical pharmacy services. ${ }^{7}$ Pharmacists were observed, and their clinical functions were classified into seven different waste categories. The authors of this study shed light on clinical pharmacy processes that have the opportunity to be standardized but do not offer recommendations for improvement. Given the varying depth and scope of clinical 
pharmacy services by institution, incorporation of the Lean principles can be challenging. This article describes the process of development, data collection, and implementation of clinical metrics to improve critical care clinical pharmacist productivity utilizing the Lean methodology.

\section{System Background and Pharmacy Key Performance Indicators Implementation}

OhioHealth Riverside Methodist Hospital is a not-for-profit 1,059 bed community teaching hospital. Representatives from the pharmacy department at Riverside Methodist Hospital participated in a week-long Kaizen event to learn about Lean principles, key performance indicators (KPI), and Gemba walks. The institution identified five KPI categories (safety, quality, delivery, productivity, and cost) from which three to five metrics were created and presented on the KPI board on a monthly basis. A morning huddle was established to set the foundation for the team and created a space to identify areas of non-value that could be turned into clinical metrics. This huddle also allowed the team to evaluate, discuss, and document metrics (Table 1 ) from the previous day. Pharmacists completed data collection for each metric by the end of their shift. These metrics were presented on the critical care KPI board which was one of five boards located throughout the institution. The purpose of the boards was to serve as a visual representation of the metric data. A schedule was developed to evenly distribute the daily presentation responsibilities, which included, collecting and analyzing the metric data, updating the KPI board, leading the morning huddle, and documenting a root-cause analysis for metrics that did not meet our minimum goals. Hospital management and pharmacy leadership embarked on a Gemba walk to view each board. The assigned presenter was responsible for discussing the metric data during the Gemba walk.

\section{Metric Development}

The metric development process occurred after the daily workflow was established. A small group of pharmacists were selected to manage metric development, monitoring, and retirement. This group established a monthly cadence to generate metrics that were a mixture of self-identified pharmacists' ideas for areas of improvement, the needs of the pharmacy department, and evidence-based guidelines. Metric generation focused on measurable outcomes and incorporating new and existing literature into our clinical practice. It was the responsibility of the group to determine the minimum percentage or quantity needed to meet the goal. To ensure metrics could be transitioned promptly at the start of each month, the group kept a list of potential metrics organized by KPI category, background description, and reporting method (Table 1). These ideas were then streamlined to ensure they were able to be measured, documented, and a report could be generated. Successes were measured daily or weekly depending on the metric and were recorded on the KPI board (Figure 1). When possible, the electronic medical record (EMR) was utilized to synthesize data and report percentages for metrics. Once a metric was ready for go-live, a standard work document, which provided a detailed process for collecting and assessing metric data, was created and disseminated. This group worked continuously to create reports, determine metric feasibility, and assess the potential impact data collection could have on daily pharmacy practice. A few of the metrics that were created and implemented by the critical care pharmacy team are highlighted demonstrating successes and lessons learned.

\section{Clinical KPI Metrics \\ Medication Reconciliation Metric}

The impact of pharmacy involvement in the medication reconciliation process has been well established but recent literature has highlighted reconciliation opportunities as patients transition out of the intensive care unit (ICU). ${ }^{8-10}$ In alignment with our institutional critical care leadership goals, our group sought to standardize the process and documentation of medication reconciliation on admission to the ICU, transfer to another level of care, and discharge to home or facility. Admission reconciliation was prioritized by our team because an estimated $40 \%$ of patients were missed at baseline. These missed opportunities may have been due in part to patients bypassing the emergency department where pharmacy technicians routinely complete medication reconciliations. This estimated number was obtained by comparing the number of direct admissions to a critical care unit from an outside facility compared to the ICU census for a 6-month period. A formal progress note with a standardized template was utilized to capture completed medication reconciliations within 24 hours of ICU admission (Figure 2). This metric was self-reported by pharmacists and classified under the KPI category of delivery. Metric successes were captured daily using EMR reports of intervention data compared to ICU census. The team met the metric if $100 \%$ of patients received a medication reconciliation within 24 hours of ICU admission. At the conclusion of the 90-day metric period, admission medication reconciliation capture increased across all units, including a nearly $50 \%$ increase in capture rate within our medical ICU and neurological critical care unit, $45.6 \%$ and $46.4 \%$ respectively, and a $100 \%$ increase within the surgical ICU when compared to the 90-day period preceding process initiation. During this time, a documented 89 hours of critical care pharmacist time on medication reconciliation events was noted, with an average of 11.13 minutes per medication reconciliation and a range of 5-45 minutes. Utilizing this KPI metric data, a proposal for a medication reconciliation pharmacy technician was taken to pharmacy leadership with the noted cost savings associated with technician salary. Following metric retirement, the process of ensuring accurate medication reconciliation has become an expectation of the ICU clinical pharmacist. Factors that promoted the success of this metric included standardized documentation, ease of reporting within the EMR, accountability tracking, and multidisciplinary support. Future development of this metric includes standardizing documentation and expectations for other ICU transitions of care including transfer and discharge. 


\section{Beta-Lactam Allergy Clarification}

Beta-lactam allergies are highly prevalent and self-reported in $8-13 \%$ of patients. $^{11-12}$ Inappropriate or inaccurate documentation of beta-lactam allergies can lead to suboptimal antimicrobial therapy with agents that are either less effective or broader spectrum than necessary. ${ }^{13}$ Clarifying beta-lactam allergies was identified as a metric in an effort to evaluate readmission antimicrobial selection and streamline documentation. Pharmacists' interventions were categorized as: allergy clarified, allergy removed, beta-lactam tolerance documented, or antibiotic therapy changed. This metric was classified under the KPI category of safety. A report was generated daily to identify all patients in an ICU with a betalactam allergy. Strategies to clarify beta-lactam allergies included patient or family interviews, review of the EMR for previously received and tolerated beta-lactam antibiotics, as well as interpreting the existing allergy for accuracy. For example, an allergy to amoxicillin documented as stomach upset would be reclassified as an intolerance, allowing for providers to appropriately prescribe future beta-lactam therapy. Additionally, if a patient had received and tolerated other beta-lactams, the antibiotic tolerated as well as the date tolerated would be added to the allergy section within the EMR. The team met the metric if $\geq 50 \%$ of beta-lactam allergies were clarified for the previous day. A total of 200 interventions were made in a two-month period: allergy clarified (46.5\%), allergy removed (7.5\%), beta-lactam tolerance documented (39\%), and antibiotic therapy changed (7\%). Of the patients who had interventions that were readmitted on antibiotics, $56.7 \%$ received beta-lactam therapy during a subsequent admission. Pharmacist intervention of beta-lactam allergies through the KPI process established a successful procedure for allergy clarification as well as initiatives to optimize the EMR to sustain this practice. Medication reconciliation and beta-lactam allergy clarifications were examples of two of our most impactful KPI metrics. Common characteristics of successful KPI metrics included actions that were evidence based, within the control of the critical care pharmacist, easily measurable targets, low documentation burden, and of high clinical significance to the team.

\section{Lessons Learned and Future Directions Blood Glucose Control}

Although many of the metrics employed have captured data that have led to positive practice changes and have shown the impact of a critical care pharmacist, there have been some metrics trialed that posed challenges. An example of a metric that added significant work to the pharmacists' day was our blood glucose metric. Blood glucose management was chosen as a KPI quality metric to highlight pharmacists' interventions to improve blood glucose control. The goal for this metric was to have $>70 \%$ of ICU patients have blood glucose values $<180$ $\mathrm{mg} / \mathrm{dL}$ for the previous 24 hours. For tracking this metric, pharmacists needed to complete multiple lines of documentation for each patient on a daily basis to specify blood glucose regimen and the type of intervention. The heavy documentation burden for each patient was identified as a barrier to the success of this metric. In addition, pharmacists do not have autonomous authority to manage blood glucose within our institution, thus the clinical success of this metric was often impacted by the prescribing providers' practice.

\section{FASTHUG Documentation}

FASTHUG is a mnemonic recognized in critical care literature that standardizes the approach for the daily assessment of ICU patients which includes evaluating feeding, analgesia, sedation, thromboprophylaxis, head of bed elevation, ulcer prophylaxis, and glucose control. ${ }^{14}$ The FASTHUG metric was selected as a KPI productivity metric to underscore the process that critical care pharmacists use to evaluate patients on a daily basis. The goal for this metric was to have had $\geq 90 \%$ of critical care patients with a FASTHUG assessment completed and documented each day. Tracking this metric also involved completing multiple lines of documentation for each patient, all of which changed daily, if not hourly. The added time burden of the documentation piece greatly impacted the overall team compliance and therefore the success of this metric.

Although both the blood glucose and the FASTHUG metrics were chosen to highlight the role of a critical care pharmacist and the impact that critical care pharmacists can provide, these metrics proved to have a large documentation burden without a clear process to identify and characterize the clinical impact. The lengthy documentation these metrics required led to an increased workload, and ultimately resulted in decreased pharmacist participation in the KPI metric or decreased time for patient care.

Acknowledging the challenges of metrics that increase daily workload, we decided to shift focus towards developing metrics that could be tracked over an extended period of time. A "Critical Care Pharmacy Dashboard" was created to focus on two to three overarching yearly goals that could be achieved by measuring smaller daily and weekly metrics with monthly progress updates. The first yearly goal evaluated by our team was to increase critical care pharmacists' professional achievements by $15 \%$ throughout the year. Professional achievements included conference attendance, poster presentations, publications, and certifications. To develop this goal and the subsequent metrics, a survey was sent to pharmacists to obtain baseline professional achievements from the previous year. The first daily metric that resulted from our yearly goal was that $>50 \%$ of critical care pharmacists had selfreported $\geq 15$ minutes of dedicated time throughout the workday to spend on professional development. This metric subsequently led to a weekly learning metric where one pharmacist from the team was responsible for distributing an article, a podcast link, or any other form of education to the group at the start of the week, then leading a brief discussion at the end of the week. To minimize daily workload, each pharmacist had the entire week to complete the education with daily tracking based on the percentage of pharmacists 
completing the education by the end of each day. The plan is to continue to utilize metrics that build on each other and provide opportunities to achieve this yearly team goal.

\section{CONCLUSION}

The Lean methodology was utilized within the critical care team at a community teaching hospital to identify and implement process improvement measures subsequently eliminating waste. Initially our team encountered difficulties with incorporating this process into our daily workflow, but we have identified recommendations to develop a sustainable method for metric development. 1) The identified metrics should be current, timely, and evidence based. Our group utilized the release of new guidelines or landmark trials to help identify KPI metrics that may change our clinical practice. 2) Metrics should be specific to your department. Several of our metrics were influenced by nursing or physician practices, beyond the scope of pharmacist control, which made it difficult to meet our daily goals. This subsequently impacted our ability to appropriately determine the root-cause and develop an action plan. We recommend identifying metrics which are within the control of your department or consider developing a joint metric if it is an interdepartmental concern. 3) Documentation should be streamlined. Labor-intensive documentation took time from patient care and resulted in decreased participation with daily documentation for the metric. 4) Metrics which do not require daily documentation should be considered. To decrease the documentation workload on our pharmacists, we created a weekly metric but identified minimum daily goals to be met as the week progressed. This method enabled each person to meet the goal over a time period of one week, minimizing the daily burden. The Lean methodology was successfully employed by our critical care pharmacy team to improve clinical processes. We provide the above recommendations for developing a sustainable process for metric development within the clinical practice setting.

Acknowledgments: None

Acknowledgement of funding source(s): None

Conflict of interest statement: The authors have no conflicts of interest to disclose.

\section{REFERENCES}

1. Lean Enterprise Institute, Inc. Available from: https://www.lean.org. Date accessed: 10 September 2021.

2. Lamm MH, Eckel S, Daniels R, Amerine LB. Using Lean principles to improve outpatient adult infusion clinic chemotherapy preparation turnaround times. Am J Health Syst Pharm. 2015;72(13):1138-1146.

3. Cima RR, Brown MJ, Hebl JR, et al. Use of Lean and six sigma methodology to improve operating room efficiency in a high-volume tertiary-care academic medical center. J Am Coll Surg. 2011;213(1):83-94.

4. Smith, B. Using the Lean approach to transform pharmacy services in an acute trust. The Pharmaceutical Journal, Vol.282, p457. URI: 10884114

5. Imai, Masaaki. Kaizen (Ky'Zen), the Key to Japan's Competitive Success. New York: Random House Business Division, 1986.

6. Shiu J, Mysak T. Pharmacist clinical process improvement: applying Lean principles in a tertiary care setting. Can J Hosp Pharm. 2017;70(2):138-143.

7. Green CF, Crawford V, Bresnen G, Rowe PH. A waste walk through clinical pharmacy: how do the 'seven wastes' of Lean techniques apply to the practice of clinical pharmacists. Int J Pharm Pract. 2015;23(1):2126.

8. Smith SB, Mango MD. Pharmacy-based medication reconciliation program utilizing pharmacists and technicians: a process improvement initiative. Hosp Pharm. 2013;48(2):112-119.

9. Wills BM, Darko W, Seabury R, Probst LA, Miller CD, Cwikla GM. Pharmacy impact on medication reconciliation in the medical intensive care unit. $J$ Res Pharm Pract. 2016;5(2):142-145.

10. Tully AP, Hammond DA, Li C, Jarrell AS, Kruer RM. Evaluation of medication errors at the transition of care from an ICU to non-ICU location. Crit Care Med. 2019;47(4):543-549.

11. SousaPinto B, Fonseca JA, Gomes ER. Frequency of self-reported drug allergy: a systematic review and meta analysis with meta regression. Ann Allergy Asthma Immunol. 2017;119: 362-73.e2.

12. Vyles D and Macy E. Self-reported beta-lactam intolerance: not a class effect, dangerous to patients, and rarely allergy. Expert Rev Anti Infect Ther. 2019 Jun;17(6):429-435.

13. Zhou L, Dhopeshwarkar N, Blumenthal KG, et al. Drug allergies documented in electronic health records of a large healthcare system. Allergy. 2016; 71: 1305-13

14. Vincent JL. Give your patient a fast hug (at least) once a day. Crit Care Med. 2005;33(6):1225-1229. 
Table 1. OhioHealth Riverside Methodist Hospital: Critical Care Pharmacy KPI Metrics

\begin{tabular}{|c|c|c|c|}
\hline KPI Metric & Category & Background & $\begin{array}{l}\text { Tracking/Reporting } \\
\text { Method }\end{array}$ \\
\hline $\begin{array}{l}100 \% \text { of patients admitted to ICU have } \\
\text { their home medications reviewed by a } \\
\text { pharmacist or medication reconciliation } \\
\text { technician within } 24 \text { hours of admission }\end{array}$ & Delivery & $\begin{array}{l}\text { Due to direct admissions and high patient } \\
\text { volumes medication lists were not always } \\
\text { completed prior to admission in the ICU }\end{array}$ & $\begin{array}{l}\text { - Self-reported } \\
\text { completion } \\
\text { documented }\end{array}$ \\
\hline $\begin{array}{l}100 \% \text { of discharge medication } \\
\text { reconciliations reviewed for patients } \\
\text { directly discharging from the ICU }\end{array}$ & Safety & $\begin{array}{l}\text { Pharmacists can have a major impact on } \\
\text { medication error reduction at time of ICU } \\
\text { discharge. This metric will show the \# of } \\
\text { missed opportunities for discharge MR } \\
\text { review due to time of transfer/workflow } \\
\text { constraints }\end{array}$ & $\begin{array}{l}\text { - } \text { Report created and } \\
\text { run daily }\end{array}$ \\
\hline $\begin{array}{l}90 \% \text { of transfer medication reconciliations } \\
\text { reviewed for patients transferring out of } \\
\text { the ICU }\end{array}$ & Safety & $\begin{array}{l}\text { Pharmacists can have a major impact on } \\
\text { medication error reduction at time of ICU } \\
\text { transfer. This metric will show the \# of } \\
\text { missed opportunities for review due to } \\
\text { time of transfer/workflow constraints }\end{array}$ & $\begin{array}{l}\text { - } \text { Report created and } \\
\text { run daily }\end{array}$ \\
\hline $100 \%$ of beta-lactam allergies clarified & Safety & $\begin{array}{l}\text { Patients are often started on alternative } \\
\text { antibiotics due to a documented beta- } \\
\text { lactam allergy. Pharmacists will identify if } \\
\text { this is a true allergy via patient interview } \\
\text { or documented tolerance to other beta- } \\
\text { lactam antibiotics in the past }\end{array}$ & $\begin{array}{l}\text { - Report created and } \\
\text { run daily to identify } \\
\text { patients with beta- } \\
\text { lactam allergies. } \\
\text { - Self-reported } \\
\text { documentation of } \\
\text { method utilized for } \\
\text { clarification }\end{array}$ \\
\hline Blood Glucose Monitoring & Quality & $\begin{array}{l}\text { The goal is to reduce incidence of } \\
\text { hyperglycemia and improve glycemic } \\
\text { control while highlighting pharmacist } \\
\text { recommendations }\end{array}$ & $\begin{array}{l}\text { - Self-reported with } \\
\text { hyperglycemic goals } \\
\text { met (Yes or No) and if } \\
\text { not, intervention } \\
\text { made. } \\
\text { - Report run daily }\end{array}$ \\
\hline $\begin{array}{l}\text { 90\% of critical care patients had a } \\
\text { FASTHUG assessment completed each day }\end{array}$ & Productivity & $\begin{array}{l}\text { Critical care pharmacists inherently } \\
\text { complete a FASTHUG assessment on } \\
\text { patients daily. This metric was an attempt } \\
\text { to quantify daily pharmacist function }\end{array}$ & $\begin{array}{l}\text { - \% is calculated based } \\
\text { on \# of iVents } \\
\text { (numerator) divided } \\
\text { by ICU census for } \\
\text { previous day } \\
\text { (denominator) }\end{array}$ \\
\hline $\begin{array}{l}75 \% \text { of critical care pharmacists have } 30- \\
\text { minute lunch + leave on time }\end{array}$ & Quality & $\begin{array}{l}\text { Intent is to encourage/ensure adequate } \\
\text { time in the workday to complete } \\
\text { expected duties and promote work/life } \\
\text { balance }\end{array}$ & $\begin{array}{l}\text { - Self-reported as Yes or } \\
\text { No }\end{array}$ \\
\hline $\begin{array}{l}50 \% \text { of IV pain medications orders } \\
\text { discontinued after } 48 \text { hours without } \\
\text { utilization }\end{array}$ & Safety & $\begin{array}{l}\text { Considering the opioid drug shortage, this } \\
\text { goal is to ensure the discontinuation of } \\
\text { unnecessary IV opioid orders. } \\
\text { Mechanically ventilated patients are } \\
\text { excluded }\end{array}$ & $\begin{array}{l}\text { - Self-reported as Yes or } \\
\text { No }\end{array}$ \\
\hline $\begin{array}{l}80 \% \text { of patients on atypical antipsychotic } \\
\text { for delirium transferred out of the ICU } \\
\text { with a taper plan documented in the } \\
\text { pharmacist hand off }\end{array}$ & Safety & $\begin{array}{l}\text { Purpose is to have a clear plan delineated } \\
\text { for medications started in the ICU for } \\
\text { delirium and avoid the inappropriate } \\
\text { continuation on transfer/discharge. } \\
\text { Excludes patients with Behavioral Health } \\
\text { consults }\end{array}$ & $\begin{array}{l}\text { - Self-reported as Yes or } \\
\text { No }\end{array}$ \\
\hline
\end{tabular}




\begin{tabular}{|c|c|c|c|}
\hline $\begin{array}{l}\text { Ability to compete order verification } \\
\text { during rounds }\end{array}$ & Quality & $\begin{array}{l}\text { Pharmacy productivity within OhioHealth } \\
\text { is defined by orders verified. By verifying } \\
\text { orders during rounds, clinical pharmacists } \\
\text { contribute towards productivity numbers, } \\
\text { offset the workload on staff pharmacists, } \\
\text { but also decrease clarification phone calls } \\
\text { from the staff pharmacists to the ordering } \\
\text { provider }\end{array}$ & $\begin{array}{l}\text { - Self-reported as Yes or } \\
\text { No and approximate } \\
\text { number of orders } \\
\text { verified }\end{array}$ \\
\hline $10 \mathrm{IV}$ to $\mathrm{PO}$ medication conversions & Cost & $\begin{array}{l}\text { Unnecessary IV medications can } \\
\text { contribute towards increasing cost of care } \\
\text { for the patient. Changing medications } \\
\text { from IV to PO can assist in cost savings for } \\
\text { the patient and the department }\end{array}$ & $\begin{array}{l}\text { - Each medication } \\
\text { documented via EPIC }{ }^{\circledR} \\
\text { iVent with the } \\
\text { following parameters: } \\
\text { Event type: Dosage } \\
\text { form change, Subtype: } \\
\text { IV to PO, Outcome: } \\
\text { Cost savings } \\
\text { - Report run daily }\end{array}$ \\
\hline $\begin{array}{l}\text { Prior to admission medication list } \\
\text { reviewed within } 24 \text { hours of hospital } \\
\text { admission }\end{array}$ & Safety & $\begin{array}{l}\text { Expectation is to enter EPIC }{ }^{\circledR} \text { iVent } \\
\text { denoting review if not already done by a } \\
\text { medication reconciliation technician. This } \\
\text { is an opportunity to identify gaps in the } \\
\text { current process (ex. number of misses } \\
\text { due to transferring from non-ICU unit) }\end{array}$ & $\begin{array}{l}\text { - Self-reported as Yes or } \\
\text { No }\end{array}$ \\
\hline $\begin{array}{l}\text { CRRT and } \mathrm{EPIC}^{\circledR} \text { iVent created after } \\
\text { antibiotic review }\end{array}$ & Safety & $\begin{array}{l}\text { Currently the EMR alerts pharmacists } \\
\text { when a patient has been started on CRRT. } \\
\text { There is a concern that antibiotic dosing is } \\
\text { not always being appropriately adjusted } \\
\text { in a timely manner }\end{array}$ & $\begin{array}{l}\text { - Run report of CRRT } \\
\text { patients. Chart review } \\
\text { to assess antibiotic } \\
\text { dosing. }\end{array}$ \\
\hline $\begin{array}{l}100 \% \text { of patients on NMBAs are } \\
\text { adequately sedated prior to initiation of } \\
\text { NMBA }\end{array}$ & Safety & $\begin{array}{l}\text { Recurring issues regarding the } \\
\text { appropriate titration of sedation prior to } \\
\text { initiation of NMBA }\end{array}$ & $\begin{array}{l}\text { - Run report of patients } \\
\text { on NMBA. Chart } \\
\text { review of patient to } \\
\text { assess sedation prior } \\
\text { to initiation }\end{array}$ \\
\hline $\begin{array}{l}\text { ICU pharmacists intervened } 10 \text { times to } \\
\text { optimize PAD medications }\end{array}$ & Quality & $\begin{array}{l}\text { Release of the PADIS guidelines sparked } \\
\text { the need to insure ongoing compliance } \\
\text { with guideline recommendations }\end{array}$ & $\begin{array}{l}\text { - } \text { EPIC }^{\circledR} \text { iVent and report } \\
\text { run daily }\end{array}$ \\
\hline
\end{tabular}

${ }^{\mathrm{a} C R R T}=$ continuous renal replacement therapy, EMR = electronic medical record, ICU= intensive care unit, IV=intravenous, $\mathrm{KPI}=$ key performance indicator, $\mathrm{MR}=$ medication reconciliation, $\mathrm{NMBA}=$ neuromuscular blocking agent, $\mathrm{PAD}=$ pain, agitation, and delirium, $\mathrm{PO}=$ by mouth. 
Figure 1. OhioHealth Riverside Methodist Hospital: Critical Care Pharmacy KPI Board
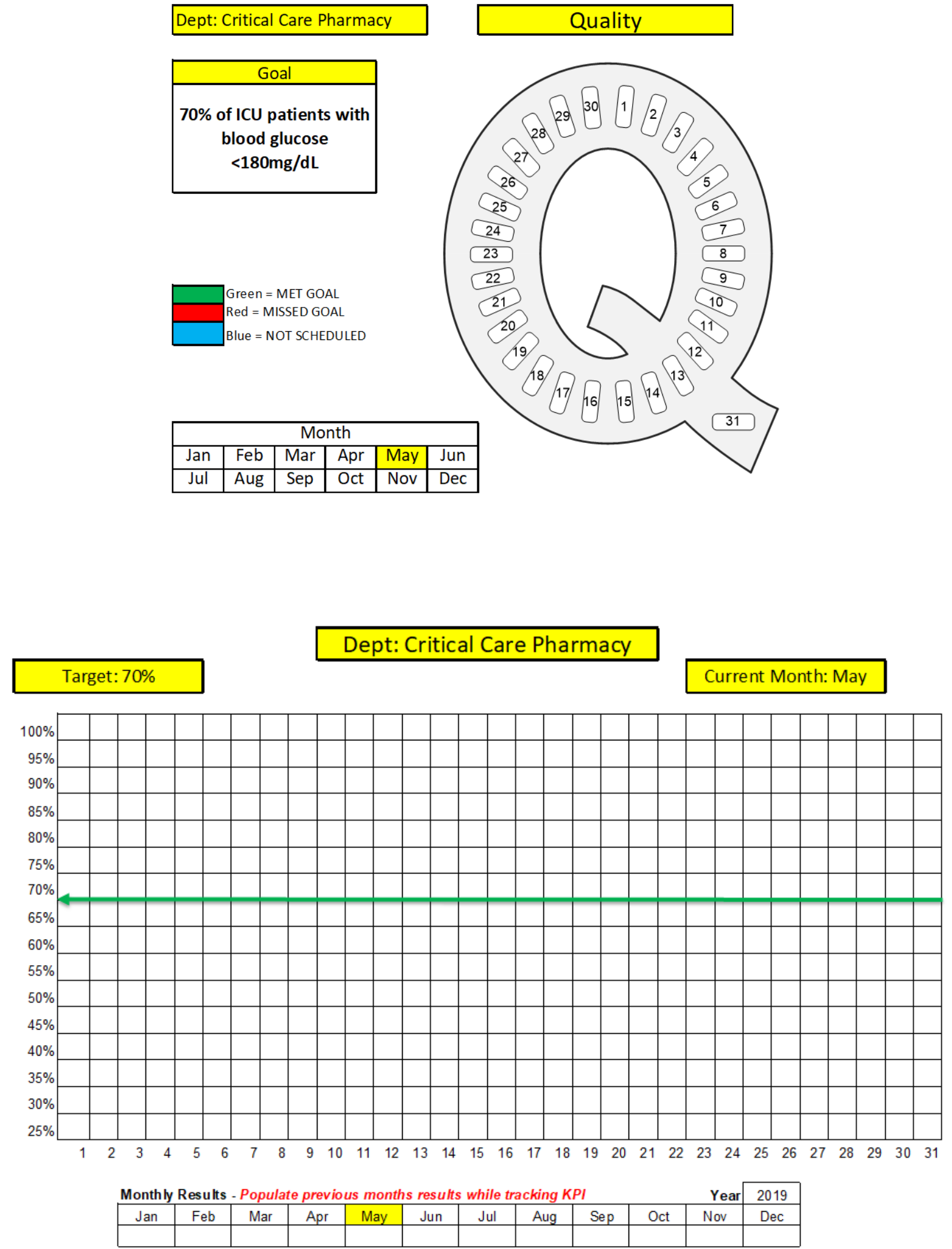

a ICU= intensive care unit, IV=intravenous, $\mathrm{KPI}=$ key performance indicator 
Figure 2. Implementation of Key Performance Indicators: Medication Reconciliation Metric

\begin{tabular}{|c|c|c|c|c|}
\hline Idea generation & $\begin{array}{l}\text { Metric creation and } \\
\text { documentation development }\end{array}$ & $\begin{array}{c}\text { Streamline documentation } \\
\text { process }\end{array}$ & Implement metric & $\begin{array}{l}\text { Run metric reports and discuss at } \\
\text { morning huddle. Complete root- } \\
\text { cause analysis as needed. Present } \\
\text { results during daily Gemba walk. }\end{array}$ \\
\hline \multicolumn{2}{|c|}{$\begin{array}{c}\text { Pharmacy driven medication reconciliation with goal for } \\
100 \% \text { of patients admitted to the ICU with medication } \\
\text { reconciliation completed by pharmacy department } \\
\text { personnel }\end{array}$} & $\begin{array}{l}100 \% \text { of pharmacists have } \\
\text { documented the time } \\
\text { spent completing a } \\
\text { medication reconciliation }\end{array}$ & \multicolumn{2}{|c|}{$\begin{array}{l}\text { Pharmacists to EPIC }{ }^{\circledast} \text { iVent medication reconciliation with time } \\
\text { documented. Huddle leader runs report and counts medication } \\
\text { reconciliations with time documented over total number of medication } \\
\text { reconciliations completed. }\end{array}$} \\
\hline
\end{tabular}

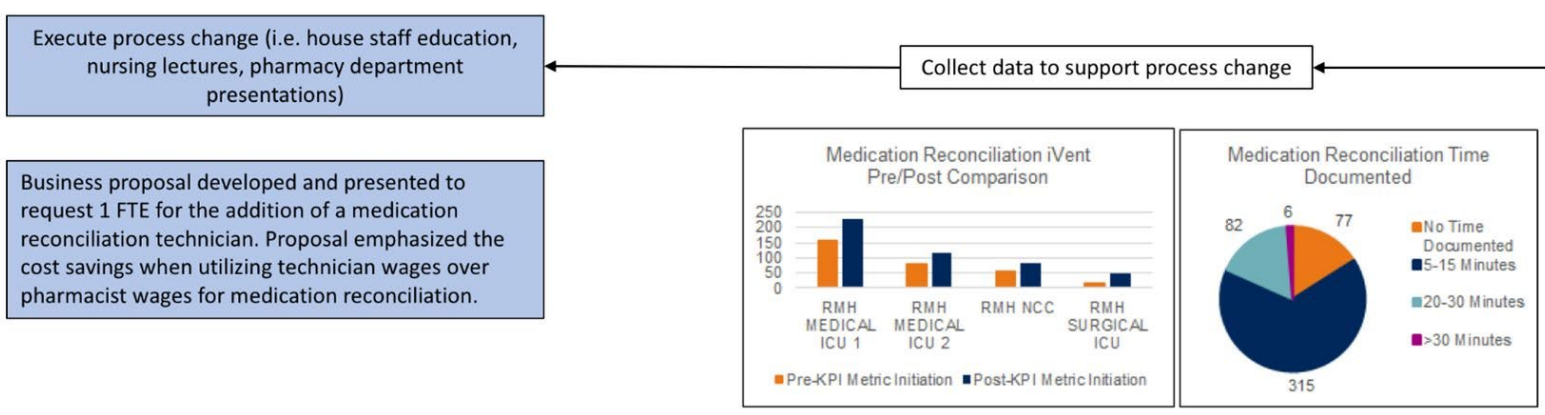

${ }^{a} \mathrm{FTE}=$ full time equivalent, ICU=intensive care unit, $\mathrm{KPI}=$ key performance indicator, $\mathrm{NCC}=$ Neurological Critical Care, RMH=Riverside Methodist Hospital. 